\title{
Particularism for Generalists: A Rossian Business Ethic
}

\author{
J. Drake \\ Creighton University
}

\begin{abstract}
A standard framework for business ethics views the inquiry as an application of major ethical theories to specific issues in business. As these theories are largely presented as being principled, the exercise therefore becomes one of applying general principles to business situations. Many adopting this standard approach have thus resisted the implementation of the most prominent development in ethical theory in recent history: that of particularism. In this article, I argue that particularist thinking has much to offer to business ethics and that standard resistance to particularist business ethics is based largely on misunderstandings. I do so by illustrating how the harbinger of particularism, W. D. Ross, countenances the practical wisdom of particularist ethics while being 1) invulnerable to standard objections to particularist business ethics and 2) compatible with the generalism of the standard approach. The Rossian business ethic is therefore one that the standard approach should be eager to include.
\end{abstract}

Key Words: particularism, generalism, holism, pluralism, W. D. Ross, prima facie duty

\section{BUSINESS ETHICS: A STANDARD APPROACH}

I suspect that anyone who has conducted either research or teaching in business ethics is familiar with the following standard (though admittedly caricatured) approach to the field. ${ }^{1}$ Business ethics, as a branch of applied ethics, is in the business of applying wisdom from general ethical theory to specific questions and issues in and surrounding business. While one cannot possibly encompass all of general ethical theory in such an endeavor, one can be sure to engage with the heavyhitters of the canon of ethics: Aristotelian virtue ethics, Kantian deontology, and Millian consequentialism. A more sophisticated approach might even include some representatives from contract theory (for example, Rawls) and the natural law tradition (for example, Aquinas), and perhaps even some discussion of relativism and multiculturalism.

In the application of general ethical theory to business, we take the central insights from such theories and see what light they may shed on the ethics of business. These insights we are all familiar with: Aristotle's doctrine of the mean, Kant's categorical

\footnotetext{
${ }^{1}$ See Arnold, Audi, and Zwolinski $(2010,560)$ for a similar description of the field and also a nice discussion of the possible relevance of non-principled ethics to business.
} 
imperative, Mill's principle of utility, Rawls's difference principle, and so on. The wisdom we are applying to business, then, seems to consist of the general principles at the heart of these major ethical theories; the resulting picture of business ethics is one of an inquiry that is, by its nature, principled. ${ }^{2}$ In business ethics, we "seek to understand the ethical contours of, and devise principles of right action for, business activity ... by choosing a normative framework and teasing out its implications for a range of issues in business." 3 One is led to believe that complicated questions concerning the ethics of advertising and sales, bribery and conflicts of interest, corporate responsibility, environmental sustainability, hiring and firing, promotion and pay, working conditions, and so on, can only be answered by the subsumption of specific cases under such general principles. Certainly no one could know the solutions to pressing problems in these areas without aid of such principles.

This standard approach to business ethics is, then, a generalist and principled approach. Standard though (something like) this approach may be, it may be due revision, not least because it does not adequately respect much of the influential work in ethical theory from the past 150 years or so. That work has, especially recently, trended away from generalist theories of ethics: "increasing influence of anti-master-principle theories of morality has been one of the most striking features of the past ten years of moral philosophy" (see Arnold, Audi, and Zwolinski 2010, 564). Case in point: ethical particularism, which is perhaps the most sophisticated expression of the pluralist tendencies of the past century, has received very little credence or application in business ethics, all while receiving the utmost respect and attention in general normative ethics and metaethics.

Though I find this standard approach to business ethics regrettable for these and other reasons, the aim of this project is not to pinpoint shortcomings of the standard approach or to provide any conclusive cure for what might ail the discipline. Rather, I hope to make the case for a more modest proposal: those who subscribe to this standard framework for business ethics would do well to bring the work of W. D. Ross further into the fold and to make Ross just as much of a staple of business ethics as are Aristotle, Kant, Mill, et al. ${ }^{4}$ In making my case, I will begin by discussing ethical particularism as a foil. As an ethical theory, particularism is maximally unprincipled (or, as I will put it to avoid the possibly pejorative connotation, nonprincipled). As such, particularism might seem wholly antithetical to the standard, generalist, principled approach to business ethics. In the next section of this article, I hope first to capture some of the common motivation for resisting the presence of particularism in business ethics by discussing some recent work on the issue. Then, I hope to demonstrate that much of this resistance is based on misunderstandings of

\footnotetext{
${ }^{2}$ There is some question about this description of Aristotle, since Aristotle is well known to have resisted a comprehensive and systematic ethic; this will be important to my argument later. Still, I expect the reader will agree that Aristotle's virtues and doctrine of the mean are often wielded in much the same manner as these other general principles.

${ }^{3}$ See Moriarty $(2017,12)$, who admits that even "the more common approach is to identify a business activity and then analyze it using intuitions and principles common to many moral and political theories" (14).

${ }^{4}$ I say "further into the fold" in view of the few, such as Audi (2004, 2008) and Carson (1993, 2005, 2010), who have done well to acknowledge the potential of Rossian business ethics.
} 
particularism and also that much of the deep insight that particularism has to offer to business ethicists is ultimately not at odds with a generalist or principled approach to ethics. Finally, in section 3, I bolster these points by illustrating how a Rossian ethic accommodates these fundamental insights of particularism without offending against the principled framework at the core of the standard approach. The result, I hope, will be that the reader will agree with me to make a home for Ross in the canon of standard business ethics.

\section{RESISTANCE TO NON-PRINCIPLED APPROACHES}

\subsection{Resistance to Particularist Business Ethics}

Resistance to non-principled approaches to business ethics is perhaps partly due to the assumption that business ethics (and ethics in general) is a principled inquiry. The standard approach is, after all, standard, and so it should not be surprising if some of its central commitments and assumptions have occasionally been unnoticed, forgotten, or unscrutinized. In his encyclopedic survey of the subject, for example, Moriarty (2017, 12-14) discusses "popular frameworks for business ethics"; they all have, either as their starting point or their ultimate goal, general ethical principles. Werhane's (2010) retrospective of the past twenty (or so) years of business ethics describes the inquiry as an exercise in building up a base of guiding principles for business. ${ }^{5}$ Lurie and Albin $(2007,196)$ seem to assume that moral dilemmas in business ethics are dilemmas "where one generally understands the values of the principles involved, but does not know how to resolve the empirical conflict between them."

These presumptions notwithstanding, it is not as though business ethicists are wholly unaware of the rise of non-principled theories in ethics or of their possible application to business. Assumed though the standard approach may often be, it has been the subject of some recent critical discussion. ${ }^{7}$ In fact, some have explicitly resisted the application of non-principled ethical theories to business-especially particularist theories. If I could gather some of the explicit resistance to particularism in business ethics, I would suggest that the resistance is grounded in three main concerns. ${ }^{8}$ First, opponents object that particularism cannot tell us, concretely, what to do in specific cases. Lurie and Albin $(2007,203)$ argue, for example, that a particularist approach to business ethics can offer us no guidance in "situations in which one simply has no idea what is the right thing to do" and "is of no real help in these cases ... where one feels one has too many conflicting duties to carry out" that

\footnotetext{
${ }^{5}$ Werhane $(2010,700)$ also says that one of the central tasks for the future of business ethics is to develop principles that are more "truly global" and to alter climates that "preclude going forward with the adoption and practice of these principles everywhere."

${ }^{6}$ Lurie and Albin (2007), to their credit, conduct a refreshingly critical discussion of the reliance on principles in business ethics. Still, I will suggest, they are among those who reject non-principled theories on the basis of misunderstandings.

${ }^{7}$ See especially Arnold, Audi, and Zwolinski (2010), Lurie and Albin (2007), and Smith and Dubbink (2011). I have also been helped by reading Gustafson (2019).

${ }^{8}$ Thanks to both Alexei Marcoux and an anonymous referee for helping me to more clearly articulate and taxonomize these concerns.
} 
"lack of moral knowledge due to lack of moral training is inherent" in many business situations, and particularism here can only "resolve such moral dilemmas by appealing to our moral sensitivities," making it "quite difficult for us to establish what ... is the right thing to do." I will refer to this type of resistance to particularism as No-Verdict resistance. Second, critics are concerned that particularism cannot tell us, concretely, how to think about what to do in specific cases. Smith and Dubbink (2011), for example, argue that we need to be able to "abstract from complexity in order to judge a particular case" (217), that "moral judgments [cannot] be made simply on the basis of a survey of circumstances of a particular situation" (225), that "organizations need to design behavioral systems in a way that emphasizes the attitudes necessary for principled judgment" (225), and that we need to "assure that particular judgments are well informed" (227) — and that all such thinking is at odds with non-principled theories such as particularism. ${ }^{10} \mathrm{I}$ will refer to this as $\mathrm{No}$ Procedure resistance. Finally, those warm to the standard approach express worry that the particularist cannot objectively support claims about what should be done in specific cases. This worry is manifest in the quoted remarks above-especially Laurie and Albin's objection that particularist ethics too heavily relies on "appealing to our moral sensitivities" and Smith and Dubbink's concern with ensuring "that particular judgments are well informed" (by principles, of course). ${ }^{11}$ I will refer to this as No-Objectivity resistance.

There may be other reasons for resisting the presence of particularism in business ethics, but I think that the thoughts that particularism provides no verdict, procedure, or objectivity pretty well run the gamut.

\subsection{The Particulars of Particularism}

To the extent that resistance to non-principled approaches to business ethics is due to an assumption that the inquiry is principled, the resistance is merely implicit. I am more concerned to address the explicit No-Verdict, No-Procedure, and No-Objectivity resistances to non-principled approaches just mentioned. I will argue in the remainder of this section of the article that such concerns arise largely from misunderstandings of ethical particularism. When the particulars of particularism are clarified, the objections to a particularist business ethic either fade away or else apply with equal force to principled approaches.

I do not believe much progress can be made on the issue without separating and distinguishing different elements of particularism which opponents may be resisting. Perhaps the most influential statement and defense of particularist thought is owed to Dancy $(2004,2009),{ }^{12}$ who characterized the opposition between particularism and generalism primarily as a disagreement about the role of principles in

\footnotetext{
${ }^{9}$ See also Kuczewski (1997) and Kaebnick (2000).

${ }^{10}$ See Smith and Dubbink (2011), who cite Herman and O’Neill in their corner.

${ }^{11}$ Brad Hooker has repeatedly raised a similar objection to particularism outside the context of business ethics.

${ }^{12}$ See Dancy $(2004,7 ; 2009,6,8,12-13)$ for the original standard characterization of the view and for the inspiration of the six definitions supplied below. See Ridge and McKeever (2016) for a helpful survey of the discussion that has developed around the work of Dancy and other particularists.
} 
moral judgment. In that same vein, this article will proceed under the following taxonomy. ${ }^{13}$

Particularism: The correctness of any moral judgment, concerning any action, is determined by specific features of the particular situation in which the action is performed.

This is opposed to

Generalism: The correctness of any moral judgment, concerning any action, is determined by a general principle (or property) which an action might satisfy (or possess).

Implicit in these opposing statements is a disagreement concerning the character of the competent moral judge: is the competent moral judge the one who, in deliberation, calls upon general principles, or not? In business ethics, the generalist would aim to show that it is impossible to manifest proper moral thought and judgment about business without the aid of general principles.

When Dancy launched particularism into the foreground of ethical theorizing, the view was built upon-but is logically distinct from-two other views. The first is what Dancy called

Holism: A feature that is a reason in one case may be no reason at all, or an opposite reason, in another. Reasons have variable relevance.

This is opposed to

Atomism: A feature that is a reason in one case must remain a reason, and retain the same polarity, in any other. Reasons have invariable relevance.

Alternatively, we could say that, according to holism, whether some feature or consideration is a reason, in any given situation, depends upon all of the morally relevant features of the situation. ${ }^{14}$ On extreme versions of the view, the very relevance of individual features of situations - not just the overall obligationsmight come about holistically, as a result of the whole situation.

The second building block to which I wish to call attention is what is standardly called

Pluralism: There is more than one kind of morally relevant property.

This is opposed to

Monism: There is only one kind of morally relevant property.

\footnotetext{
${ }^{13}$ Thanks to Robert Audi for helping me to formulate these characterizations in a way useful for the purposes of this article. This way of framing the debate makes use of what Ridge and McKeever (2016) call Anti-Transcendental Particularism.

${ }^{14}$ See also Arnold, Audi, and Zwolinski (2010, 564). As I will make clear later, I think that this alternative characterization is more helpful, and more fundamental to what is really at issue. By "reason" here, particularists mean normative reason: a consideration that counts in favor of a response or a normatively relevant feature. Most particularists take reasons to be the fundamental building blocks of ethical reality and requirement.
} 
Whereas monists are prone to assert that there is one basic, fundamental, or intrinsic good (such as good will or pleasure), pluralists will deny this; whereas monists are prone to assert that there is one basic, fundamental, overarching obligation (such as the categorical imperative or the principle of utility), pluralists will deny this (see also Arnold, Audi, and Zwolinski 2010, 562).

With these six distinct moving parts now separated but simultaneously in view, we can see that ethical particularism is a theory of the nature of ethical judgment, supplemented by two views (holism and pluralism) about the nature of ethically relevant features. The overall picture, in a nutshell, is that ethically relevant features - those facts or features that determine what we should do in any given case-are varied both in kind and behavior and that the structure of good ethical judgment mirrors this fact. That is, the landscape of ethical reality is largely complex and non-principled, and so, then, is good judgment of ethical reality (see also Arnold, Audi, and Zwolinski 2010, 561-62, 565). The standard approach to business ethics, by contrast, seems to assume the truth of generalism, atomism, and monism. On this view, the landscape of ethical reality is largely principled, stable, and uniform; good ethical judgment in business ethics is that which applies stable and uniform principles and values to concrete cases.

Since generalism is really what seems to be most at the heart of the standard approach to business ethics, it may come as no surprise that many business ethicists reject particularism out of hand. According to many, after all, particularism is just the simple denial of generalism, and so it may seem also to be at odds with the standard approach. I think that this attitude, though accurate, does not do justice to the complexity of the tension. Indeed, as I will demonstrate more thoroughly in section 3, the theory of W. D. Ross challenges the simple packagings just mentioned. As I noted above, it should be clear that particularism is logically distinct from holism and pluralism. Despite the fact that particularism has often been established on the back of the merits of holism and pluralism, I shall demonstrate that Rossian ethics should be considered holistic and pluralistic despite its generalism. Although Ross is in many ways the harbinger of particularism, he himself remained a generalist: he held that the application and comparison of fundamental moral principles in particular cases is "the only guide we have to our duty" (Ross [1930] 2009, 42; see also Stratton-Lake [2002] 2007, xii). This generalism notwithstanding, Ross ([1930] 2009) also endorsed pluralism and holism: he held that there are "various" and "often conflicting types" (23) of duty and also that "being one's duty is a toti-resultant attribute, one which belongs to an act in virtue of its whole nature and of nothing less than this" (28; see also Stratton-Lake [2002] 2007, xii-xiii). The possibility of this combination of views, I will argue, warrants more attention and promises to bear fruit in business ethics.

As I have just foreshadowed, I ultimately hope to show how Rossian ethics itself complicates the standard dialectic concerning the presence of particularism in business ethics. At present, though, I wish to make three initial remarks which I hope will leave you puzzled about standard resistance to particularism. The first thing that I hope will strike the attentive reader about the core of particularism is that it is not a normative ethical theory: it is not a theory about what things are right and 
wrong, good and bad, and so on. Neither is particularism a decision-making procedure or model of ethical deliberation. Rather, particularism is a view about the metaphysics of ethics: it is a view about the nature of the right and the good, and reasoning thereof (see Dancy 2004, 15). This fact about particularism is often overlooked, but it speaks directly to No-Verdict and No-Procedure resistances mentioned earlier. Both No-Verdict and No-Procedure resistances to particularist business ethics essentially charge it with being an ineffective normative ethical theory. But, since particularism is not a normative theory at all, this charge is misguided. Both types of resistance, then, commit what Ryle (1949, 5-7) originally called a category mistake: they treat something of type $F$ as if it belongs to type $G$. No-Verdict and No-Procedure resistances to particularism do just that: they treat particularism as a normative theory and then accuse it of being a poor normative theory-all while particularism is not in fact a normative theory. This makes about as much sense as charging modern chemistry with being a poor cookbook, or Keynesian economics with being a poor business model, or stakeholder theory with being a poor guide to profitability. The criticism has the form " $X$ is a poor $G$ "; such criticism is clearly misplaced if $X$ is in fact not a $G$ at all (and is instead an $F$ ).

The second initial remark I would like to make is an observation about what would falsify particularism. Particularism is occasionally caricatured as the view that there are no true ethical principles and straw-manned as supporting this view only by attacking any ethical principles supposed to be true (for one example, see Smith and Dubbink 2011, 207, 213-16). But we have already noted that, in its standard form, particularism is the simple assertion that good moral thought and judgment do not depend on general principles. ${ }^{15}$ This assertion is largely established by appeal to holism, with an accompanying principle of moral epistemology. In view of the apparent truth of holism, Dancy $(2004,80)$ asks of generalist theories,

Is it possible for the epistemology of a domain to come apart in this sort of way from its metaphysics? It is natural to think that were this to be the case, a peculiar sort of dislocation would have emerged. The canons of rationality for a given domain would not be directly related to, or be held in place by, the way that domain is itself structured.... But no such explanation is available in the case that we are officially concerned with here, namely the move from the domain of moral metaphysics (supposedly atomistic) to the domain of reasons for action and belief (supposedly holistic). I conclude that it is safe to think that if either of these two domains is holistic, so must the other be.

Here Dancy is laying out the essence of the original standard case for particularism. The ultimate line of reasoning is as follows: holism is true, and if holism is true, it would be an epistemological mystery if generalism were true. It would be a mystery

\footnotetext{
${ }^{15}$ See Dancy $(2009,1)$, who says that "the strongest defensible version, perhaps, holds that though there many be some moral principles, still the rationality of moral thought and judgment in no way depends on a suitable provision of such things; and the perfectly moral judge would need far more than a grasp on an appropriate range of principles and the ability to apply them."
} 
if the rationality of judgment and knowledge in ethics did not depend on making an epistemic connection with ethical reality - if it did not depend on accurately reflecting on the way that ethical features really work. Since ethical features operate in a non-principled, variable manner, it would be a mystery if the rationality of ethical judgment depended upon the supply and discharge of unvarying principles (see also Williams 1985, 16-17; Little 2000; Arnold, Audi, and Zwolinski 2010, 565).

To meet head-on the challenge to standard business ethics posed by particularism, then, one should not indict it for silence on matters on which it never intended to speak. As we noticed, to establish a generalist business ethic, one needs to show that it is impossible to exercise good reasoning about the ethics of business without the aid of principles. If the standard case for particularism is on the right track, this will involve refuting either holism or the alleged connection between holism and particularism. ${ }^{16}$ All of this should lead us to wonder why business ethicists have tried to resist particularism by claiming that it provides no verdict, procedure, or objectivity - since none of those objections employ either of these straightforward strategies.

The third and final initial observation I should like to make is that, once the core commitments of particularism are clearly in view, we can see that a crucial claim on which No-Objectivity resistance is based is clearly false. Particularism is a view about the nature of moral judgment and morally relevant features-features that are relevant to whether acts are right or wrong. No-Objectivity resistance charges particularism with being unable to provide objective support for claims about what we should do - about which acts are right and wrong. But just what does one adduce in trying to support a claim about what should be done in a specific case? Presumably, one adduces morally relevant features - features that make the act right or wrong. Although particularism is not in the business of telling us which specific acts are right or wrong, it $i$ in the business of telling us what makes acts right or wrong; it is in the business of inquiring as to what sorts of considerations could be marshaled to objectively support the claim that an act ought or ought not to be done. This is often lost on critics of particularism, I think, because they conflate either the holism or the pluralism of particularism with the refusal to give an answer (or with insisting that there is no answer) as to what makes acts right or wrong. We can see now that this is not so: saying that the behavior of morally relevant features varies from case to case, or saying that there is more than one kind of morally relevant feature, obviously does not entail that there are no objective answers to questions about what is right or wrong or that there is no way to objectively support answers to such questions. Of course, one might think differently if one insisted that all objective support for claims about what should be done must come in principled form; one who so insisted would, at this point, clearly be begging the question against the particularist.

I tentatively conclude, then, that the usual forms of resistance to particularist business ethics are based on misunderstandings of particularism; as a result, they are

\footnotetext{
${ }^{16}$ Ridge and McKeever $(2005,2006)$ should be acknowledged for an especially good effort at the latter strategy.
} 
either implausible or infelicitous. To be clear, this has not been a criticism of the standard approach to business ethics per se; as yet, I have said nothing about the overall merits or deficiencies of the standard approach. Instead, I have limited my concerns to critiquing certain arguments those fond of the standard approach have often given against particularist business ethics, and I have tried to show that those arguments are unsuccessful.

\subsection{The Practical Wisdom in Particularism}

An obvious question at this point is, if particularism is not a view about what we should do or value, and it is not a view about how we should make decisions about what to do or value, then what benefit could it possibly confer on the inquiry of business ethics? What could a particularist business ethic even be? Can we not simply recast No-Verdict, No-Procedure, and No-Objectivity resistances by saying that ethical particularism indeed cannot accomplish these feats in the practical manner in which any good business ethic should-? If particularism is not ultimately a (normative) theory of practical reasoning, then are not charges that particularism has no practical wisdom to offer business ethics ultimately correct? Have I not made particularism invulnerable to some lines of attack only by making it vulnerable to one even more devastating?

In this section, I want to suggest that the practical wisdom of particularism, and its import to business ethics, rests in what may be thought of as three by-products of the central argument for particularism. These are the thoughts that 1) holism is a plausible view of the nature of morally relevant features; 2) pluralism is a plausible view of the nature of morally relevant features; and 3) in many cases, the principles to which we may appeal in business ethics are either questionable, defeasible, or unnecessary. Taken together, these three things lead to quite commonsensical thinking about ethical reasoning in general: in any particular situation, the ethical landscape may be quite complex, and it may not seem possible for us to subsume every case under one general principle or basic value; still, we often feel able to confidently render correct verdicts about what to do in such cases. I will then argue (in the third and final section of the article) that W. D. Ross captures these three pieces of practical wisdom while still endorsing a generalism which is friendly to the standard approach to business ethics.

I will treat these three by-products in turn. Holism in ethics, though perhaps most sophisticatedly expressed in the past century, has a rich ancestry. In the Republic, for example, Plato's Socrates provides a well-known counterexample to an analysis of justice, on which "unconditionally it is speaking the truth and paying whatever debts one has incurred" (Plato 1997, 331c-32a). ${ }^{17}$ But the counterexample (returning a borrowed weapon to a man who has gone mad) does not merely refute the unconditional principle in a brute manner. Plato's Socrates seems prepared to accept that, in general, the fact that you borrowed this object from someone obligates you to return it; but in some cases, that obligation is defeated or defused by another feature of the situation (that the lender of the weapon has gone mad, for example). There are

\footnotetext{
${ }^{17}$ I am indebted to Paul Woodruff for helping me to see the holism in Plato's ethics.
} 
also clear elements of - or at least similarities to-holism in Aristotle's doctrine of the mean. Holism should therefore not be viewed, I contend, as some newfangled wrinkle in ethical theory conjured up by faddish anti-generalists. It is a way of viewing moral metaphysics that is traceable to the very foundations of Western philosophical ethics and that has stood the test of time, although it has recently been attracting a bit more explicit attention.

The intuitive appeal of holism is not difficult to appreciate. It will resonate with anyone who has ever responded to an assertion as to what ought to be done in a certain situation with a thought of the form "But what about...?!" One way of putting the question about the truth of holism is as one about how right acts get to be right. Specifically, are acts made right in virtue of their whole character or rather by some subset of features included in their character? Holism implies that acts are made right (or wrong) in the former manner; atomism implies the latter. Atomists will pick their favorite morally relevant features (usually there is ultimately just one, since atomists are usually monists) and make their conclusions about the rightness or wrongness of an act solely based on the presence or absence of those features - disregarding all the rest. For example, the Kantian, at the end of the day, will ask one question: on what maxim was the action based? We can know whether the act in question is right or wrong the moment we know the moral status of the maxim - all other features of the action can be ignored. But does this atomistic thinking really ring true or seem useful? Suppose that you have identified that the maxim on which this act was based was that of fulfilling a promise. Do you know all that you need to know in order to determine the rightness or wrongness of the act? It is very tempting to think not. What about the effects of this choice on the profitability of our company? On the morale of our employees? The local environment? What about our duties to our local community? What if we also promised a local business partner that we would not do this act? What if the act commits an injustice against a competitor? What if it would be rash? As Ross ([1930] 2009, 18) himself notes, it seems that "it must of course be admitted that such cases exist"- complicated cases in which an act could be subsumed under several, potentially conflicting, principles. It is hard to resist the idea that the act in question will be made right or wrong in virtue of the interaction among all of these features; once they are all in view, it would seem a bit stubborn — if not deliberatively irresponsibleto discard them as insignificant. ${ }^{18}$

The point, then, is that holism is not only a plausible view of the nature of moral reality; it also provides some crucial insight as to what sensible and mature moral reasoning looks like. Atomism encourages a kind of moral myopia; holism

\footnotetext{
${ }^{18}$ Here I pick on Kantianism (and, in the next paragraph, on hedonism), but I leave it to the reader to see how a similar critique might have been raised against other favored atomistic (or monistic) theories. Many thanks to an anonymous referee who observed that the crucial difference between the Rossian and the Kantian here might be better expressed as a disagreement about the ordering and stability within the hierarchy of values. I think that it is true that the disagreement can be adequately described in this way; as I note in section 3.1, holism comes in many varieties and degrees — one of which is to allow flexibility and instability within the hierarchy of values. If what I describe as a "holistic" aspect of theory seems to some better taxonomized as a value commensurabilist/incommensurabilist (for example) aspect of theory, I would not strongly dispute that taxonomy.
} 
encourages a kind of moral imagination and sensitivity. ${ }^{19} \mathrm{~A}$ similar point can be made about pluralism. It is difficult to remain steadfast to the idea, especially in business, that there is only one kind of morally relevant feature. Do we really believe, for example, that the only things worth considering when deliberating about who to hire are those things that would cause pleasure and pain? Whose pleasure and pain? What if we already contracted the job to Jones-is honoring our contract not relevant to our deliberation, independent of the pleasure or pain brought about by doing so? "It may be said," Ross ([1930] 2009, 18) notes, "that besides the duty of fulfilling promises I have and recognize a duty of relieving distress." What if hiring Jones would constitute prejudicial discrimination against Smith and would therefore be unjust - do we not think that this is yet another consideration of importance, independent of both already mentioned? What if we last year wrongfully terminated White and we now have the opportunity to repair that wrong by returning him to employment-is not the prospect of righting past wrongs yet another important feature? It becomes difficult to accept the idea, with all of these considerations before us, that our task is simply to trace out the pleasure and pain resultant from each facet of the situation; likewise, it becomes difficult to resist the impression that our task is rather to weigh the value of the resulting pleasure/pain against the (distinct) values of honoring our agreement, not discriminating, and righting our wrongs. And if we do resist this latter impulse, it is surely not without some sense that we incur a moral risk: we run the risk of ignoring and leaving unaccounted a multiplicity of morally relevant features - and therefore also of making the wrong choice.

Finally, a similar point can again be made with respect to dependence on standard ethical principles in business. Anyone who has ever doubted that a given moral principle could be applied to every situation or felt that there must be an occasional (rare!) exception to even a very sensible moral rule, will be sympathetic to this point. And again, this surely reflects how many of us really think and feel about the ethics of business. To discuss one such rule that has received attention from business ethicists: you should not deceive those you are in negotiations with; this is a fine principle, to be sure. But is the fact that an act (stating your best offer for this house, for example) would be a bit of deception always a good reason not to do it? Is it always a conclusive reason not to do it, such that it always creates an obligation not to do the act which would be deceptive? What if, for example, you know that your negotiating partner is deceiving you (misstating the lowest possible offer they would accept) in a way that is harmful to you and that reciprocating with some deception of your own is the only way to defend against that harmful act? Is it really clear that these negotiating practices are categorically wrong? ${ }^{20}$ What if - to vaguely describe another kind of case-deceiving my business partners in this case is the only way to

\footnotetext{
${ }^{19}$ See Werhane (1999) on the importance of moral imagination in business ethics; see also Arnold, Audi, and Zwolinski (2010, 565). These remarks should not be taken to suggest that the Kantian has no resources for sorting through the complexities of the moral landscape I discuss; Audi $(2001,2004)$ has done well to show how flexible such a theory can be. Still, I expect that the reader will recognize as familiar the kind of implementation of Kantian theory at which I gesture here.

${ }^{20}$ Here I draw on Carson (1993), whose discussion of bluffing relies on holism (though he does not use that technical term) and well coheres with the sort of Rossian business ethic I will sketch in the next section.
} 
save our company and, ultimately, their jobs and livelihoods (not to mention the livelihoods of and benefits to all of our employees, suppliers, consumers, et al.). Usually, of course, we should not act deceptively. Surely, though, we all feel the pull of the thought that the fact that this act would be deceptive does not obviously win the day in every deliberative process it enters. ${ }^{21}$

The practical wisdom of particularism, I have been trying to suggest, rests not primarily in its exposing shortcomings in generalism. (Indeed, as a generalist myself, I am for present purposes content to leave it entirely to the reader to judge whether particularists have enjoyed any success on that front.) Instead, its wisdom rests in 1) its observation that we must examine the whole character of an act-not just one or two fetishized features - in orderto determine its moral status; 2) its observation that there may be many different kinds of things that are relevant to whether an act is right or wrong and that we have no epistemic right to assume in advance that we can reduce the whole inquiry down to one class of features; and 3) its arousing our suspicion that many of our treasured principles are, at least in some cases, either falsified, defeated, or inapplicable. This wisdom, I have also suggested, is really wisdom that we already possess; natural, commonsensical thinking about business ethics bears out these insights. So, despite resistance to particularism from those who adopt the standard approach, it seems clear that there is much in particularism that the standard approach should be eager to accommodate.

\section{A ROSSIAN BUSINESS ETHIC}

Still, it may seem difficult to overcome that initial barrier: particularism seems to be at odds with the core of the standard approach. The standard approach says that generalism is true; particularism says that generalism is false. I wish now to make good on my claim, which I foreshadowed in section 2.2, that the ethics of W. D. Ross can offer business ethicists most of what they should find appealing in particularism while still retaining the generalism of the standard approach. More specifically, attention to Rossian theory can reveal how those in the standard approach may gladly endorse pluralism and holism (and experience the benefits of so doing) without forfeiting their generalist convictions. I will first give a brief account of Ross's general ethics, illustrating more thoroughly how it adheres to generalism while accepting holism and pluralism. I will then briefly explain how a Rossian business ethic can face up to the challenges business ethicists have raised to particularist business ethics in the forms of the No-Verdict, No-Procedure, and No-Objectivity resistances discussed earlier. Along the way, I will try to illustrate the various ways in which Ross's ethics is ecumenical, making a concerted effort to accommodate the various wisdoms of the ethical theories which the standard approach already welcomes. The cumulative result, I hope, will be that business

\footnotetext{
${ }^{21}$ One might, at this point, think that our task is to discern the more finely tuned principle that captures the exceptional cases. But what confidence should we have that there will not be seeming exceptions to that finely tuned principle? And with each fine-tuning, what confidence should we have that we are really outlining a fundamental principle of negotiation, rather than exercising our judgment as to when the more coarse-grained principle applies or succeeds?
} 
ethicists will warm to the idea that Rossian ethics should be a business ethics staple—even on the standard approach.

\subsection{Ross: A Pluralist, Holist, Generalist}

Ross's core innovation in and contribution to ethical theory is the idea of what may be called the normatively contributory. He was, in many respects, the first to take seriously, deeply explore, and build ethical theorizing upon the idea that there might be things which, though deontic in nature, are not themselves right or wrong and yet contribute to the overall rightness or wrongness of an act (or the creation of a duty). ${ }^{22}$ Ross's (admittedly unhelpful) term for this idea was prima facie duty, and he enumerated seven basic such-seven basic, general features which an act could have, which could contribute to the rightness or wrongness of that act. An act could be 1) a fulfillment of a promise, 2) a reparation of a wrong, 3) a returning of good service, 4) a bringing about of a just distribution, 5) a benefiting of others, 6) a benefiting of oneself, or 7) an injuring of others (for the landmark explication, see Ross [1930] 2009, 18-20). Ross was not stubbornly committed to this particular list; he was willing to consider, for example, that duties 4-7 could be reduced to the two more general duties of producing the good and precluding the bad (Ross [1930] 2009, 23, 27). Still, he resisted the thought that the basic prima facie duties should be reducible to or capturable by one fundamental principle:

There is no reason to anticipate that every act that is our duty is so for one and the same reason. Why should two sets of circumstances, or one set of circumstances, not possess different characteristics, any one of which makes a certain act our prima facie duty? When I ask what it is that makes me in certain cases sure that I have a prima facie duty to do so and so, I find that it lies in the fact that I have made a promise; when I ask the same question in another case, I find the answer lies in the fact that I have done a wrong. And if on reflection I find (as I think I do) that neither of these reasons is reducible to the other, I must not on any a priori ground assume that such a reduction is possible (Ross [1930] 2009, 24).

Although not as frequently discussed, Ross held a similar view of goodness: he observed four basic goods (virtue, justice, knowledge, and happiness), which are irreducible to any other and from which all other goods may be derived (134-41). ${ }^{23}$

Ross's ethics is, then, undoubtedly pluralistic: it plainly holds that there is more than one kind of morally relevant feature, whether we are discussing rightness or goodness. The sense in which Ross's ethics is holistic is less straightforward. If we accept Dancy's (somewhat extreme) characterization as definitional, then Ross will not count as a holist: Ross seems not to seriously consider (or conclusively reject) the idea that, for example, the fact that I promised to do it might sometimes fail to generate some prima facie rightness in its favor, or might even generate some prima

\footnotetext{
${ }^{22}$ See Dancy $(2004,15-37)$ for the best technical discussion of this notion; see Arnold, Audi, and Zwolinski (2010, 563-64) for a helpful discussion of relevance to business ethics.

${ }^{23}$ Although Ross $(1939,283)$ later abandoned the view that happiness, construed as pleasure, is intrinsically good, the basic mechanics of the view remained.
} 
facie wrongness against it. But, as Dancy (2004, 7-10) notes, the fundamental commitment of holism is the idea that the behavior of morally relevant features is variable, and so there is really a spectrum of views that may be considered holistic. There are at least two significant senses in which Ross holds that the behavior of morally relevant features is variable. First, Ross denies, for any given prima facie duty, that it constitutes an absolute, exceptionless, unconditional duty. Indeed, his alternative term for the notion of a prima facie duty was conditional duty. According to Ross, the fundamental moral rules are not absolute; each particular basic duty will likely win out in some cases and lose out in others. This is a striking departure from standard atomistic ethical theories. According to Kant, for example, one must never violate the categorical imperative; according to classical utilitarians, one is always required to maximize utility; and so on. The second significantly holistic aspect of Rossian ethics is in its denying that the prima facie duties always have the same weight in every case (Ross [1930] 2009, 17-18, 41-42, 46). In most cases, for example, the duty to keep our promises is quite stringent; in other cases, it might be a bit paltry. The prima facie duty of fidelity (or any other) does not contribute the same degree of prima facie rightness or wrongness to every act which is an instance of its kind.

These technicalities aside, Rossian ethics clearly exhibits the practical wisdom of holism discussed earlier: he holds that whether an act is right or wrong is the result of its whole nature, rather than any individual aspect of its nature taken in isolation. ${ }^{24}$ I think, therefore, that it is fair to characterize Ross as a holist in the sense that has been important to this discussion.

Now, can Ross really countenance these particularist wisdoms while remaining a generalist? I see no reason for thinking that he cannot. Of course, this will depend somewhat on what counts as a principle (for examples as to how this might make a difference, see Schneewind 1970, 249-50; Smith and Dubbink 2011, 216, 219). But surely claims such as "It is right to keep promises," "There is a duty to benefit others," "Do not harm others," "See to it that the virtuous are happy," and "Knowledge is good" count as general principles, if anything does, and Ross clearly accepts such claims. Indeed, he builds his theory upon them. Is accepting these general principles in contradiction with saying that rightness is a feature of actions resulting from their whole character or that there are many different kinds of morally relevant features? Clearly not; indeed, one might think that the most natural way to genuinely respect each of these principles is to treat them as contributing prima facie rightness/wrongness or goodness/badness to an act or object. Is it right to fulfill promises? Surely-although not unconditionally. Does this fact entail that any act which would be the fulfillment of a promise is required, regardless of any other seemingly important features the act may possess? No; we can say that it is generally, although not unconditionally, right to fulfill promises, in the following sense: one is required to perform an act that would be the fulfillment of a promise, provided that that act possesses no other feature of a

\footnotetext{
${ }^{24}$ Ross's ([1930] 2009, 28, 122) way of putting this was to say that whether a specific act is ultimately our actual duty is a toti-resultant property.
} 
morally significant kind such as to make the character of the act, evaluated on the whole, wrong. ${ }^{25}$

\subsection{Particularism for Generalists}

I take it that this examination of Ross, though brief, makes a good case that his is a holist, pluralist, generalist theory. I wish now to quickly illustrate how a Rossian business ethic is invulnerable to the three types of criticism earlier raised to a particularist business ethic —or at the very least, it is not anywhere near as vulnerable.

According to No-Verdict criticism, a particularist business ethic would not actually render verdicts about what we should and should not do, and therefore could offer no practical guidance. Ross's theory is chock-full of practical guidance on firstorder questions of what to do. He says, for example,

What lends colour to the theory we are examining, then is ... the exceptional cases in which the consequences of fulfilling a promise (for instance) would be so disastrous to others that we judge it right not to do so. It must of course be admitted that such cases exist. If I have promised to meet a friend at a particular time for some trivial purpose, I should certainly think myself justified in breaking my engagement if by doing so I could prevent a serious accident or bring relief to the victims of one.... [Or if], so far as I can see, I could bring equal amounts of good into being by fulfilling my promise and by helping some one to whom I had made no promise, I should not hesitate to regard the former as my duty (Ross [1930] 2009, 17-18). ${ }^{26}$

In offering analyses of such examples, I think that we can see that a Rossian business ethic could also face up to No-Procedure concerns about particularism in business. A Rossian business ethic could indeed offer practical guidance as to how to deliberate in specific cases. In the first instance-and that which I find most helpful-the Rossian does this by example. But for those who find this a bit too Aristotelian, it should be observed that Ross also provides support for thinking that there is a (loose) hierarchy among the basic duties and goods. In the realm of the right, duties of reparation, gratitude, and fidelity generally trump duties of justice, non-maleficence, beneficence, and self improvement; in the realm of the good, the good of virtue generally trumps that of justice, knowledge, and pleasure. ${ }^{27}$ Although these are not rigid rules that allow any comprehensive systematization of moral thought, it could hardly be denied that, if true, they provide helpful heuristics.

What of No-Objectivity criticism, that a particularist business ethic would be unable to objectively support claims about what one should or should not do? Even if

\footnotetext{
${ }^{25}$ On the matter of what sort of deontic logic might make this possible, see Horty (2012) and Bonevac (2016).

${ }^{26}$ See also the very practical, Ross-inspired deliberative process developed by Audi (2004), briefly discussed by Arnold, Audi, and Zwolinski (2010, 571).

${ }^{27}$ In that order-or so I say. See Ross ([1930] 2009, 18-19, 22, 26-27, 30, 39, 41-42, 137, 139, 144, 146-49, 153-54). There is most question, in my mind, about the ordering within the first three 'special' obligations, the comparative ranking of justice and non-maleficence, and the comparative ranking of justice and knowledge.
} 
a Rossian business ethic produces such verdicts, and helps us deliberate to such conclusions, it may yet be unable to justify them. Again, I think that Ross's own discussion is our best evidence that this is not so. Of the first example discussed just above, he says,

And the supporters of the view we are examining hold that my thinking so is due to my thinking that I shall bring more good into existence by the one action than by the other. A different account may, however, be given of the matter, an account which will, I believe, show itself to be the true one. It may be said that besides the duty of fulfilling promises I have and recognize a duty of relieving distress, and that when I think it right to do the latter at the cost of not doing the former, it is not because I think I shall produce more good thereby but because I think it the duty which is in the circumstances more of a duty. This account surely corresponds much more closely with what we really think in a situation (Ross [1930] 2009, 18).

Is this the type of objective support that would satisfy critics offering No-Objectivity resistance to non-principled business ethics? It does indeed give an account of what makes the act in question right. But some find the manner in which Ross arrives at this claim suspect: it might appear that he arrives at it merely by asserting it, or, as Lurie and Albin $(2007,203)$ criticize, "by appealing to our moral sensitivities."

This brings us to a point where we can no longer leave unaddressed Ross's intuitionism. ${ }^{28}$ I will not propose any definition of intuitionism here. Instead, I will identify two uncontroversially intuitionist aspects of Ross's theory. First, there is what has been called Ross's methodological intuitionism, which holds that, even if there are basic general ethical principles, there are no absolute rules that definitively instruct us how to resolve apparent conflicts among those general principles. For Ross, this meant, primarily, that the plurality of basic prima facie duties and intrinsic goods could not be systematized into any rigid, unyielding hierarchy. Instead, the comparative weighting of the basic duties and goods (along with the determination of the basic duties and goods in the first place) is, according to Ross, self-evident: it can be determined and grasped via sufficiently careful attention and reflection.

In saying that there are no meta-rules in ethics, and instead that our apprehension of duty is self-evident, is Ross not merely stipulating what has just been criticized (namely, that the non-principled ethicists can only appeal to intuition and ask us to agree)? I think not — at least, Ross is not stipulating anything not widely accepted by the ethicists who dominate the standard approach. At the heart of Rossian intuitionism is the claim that theory alone will not determine with certainty concrete verdicts about what to do in specific cases. Every theory must be implemented or applied, every case interpreted or examined, and this is a matter of pure judgment or thought. Ross ([1930] 2009, 41-42) says,

Every act therefore, viewed in some aspects, will be prima facie right, and viewed in others, prima facie wrong, and rights acts can be distinguished from wrong acts only as being those

\footnotetext{
${ }^{28}$ See Stratton-Lake ([2002] 2007, 2016) for helpful discussions of intuitionism in Ross and in general.
} 
which, of all those possible for the agent in the circumstances, have the greatest balance of prima facie rightness ... over their prima facie wrongness.... For the estimation of the comparative stringency of these prima facie obligations no general rules can, so far as I can see, be laid down. We can only say that a great deal of stringency belongs to the duties of "perfect obligation"- the duties of keeping our promises, of repairing wrongs we have done, and of returning the equivalent of services we have received. For the rest, "[the decision rests with perception]." This sense of our particular duty in particular circumstances, preceded and informed by the fullest reflection we can bestow on the act in all its bearings, is highly fallible, but it is the only guide we have to our duty.

Ross here approvingly cites Aristotle as another who holds that our ethical theory cannot be so completely systematized that no exercise of judgment is required on the part of the one welding ethical theory. But Ross has not only Aristotle to call upon in this matter. Brink (2018, 12-13, 23, 53-54) has illustrated how Mill held that the respective quality of higher and lower pleasures could be determined only by the competent judge, that the general tendencies of actions to produce utility are evidenced by the history of human experience and agreement thereabout, and that his utilitarianism is not a theory which lays down a decision-making procedure to which we can appeal to definitively support claims about what ought to be done. ${ }^{29}$ Audi has done well to show that intuitionism is compatible with, if not already inherent in, standard Kantian deontology and Rawlsian contract theory. If what business ethicists endorsing the standard approach find wanting in non-principled ethics is a fully systematized method of ethical judgment, it would appear that they should also find the standard approach wanting (see, respectively, Audi 2001; Arnold, Audi, and Zwolinski 2010, 566-71). ${ }^{30}$

The point of the immediately foregoing is not that Rossian intuitionism is a correct epistemology of ethics. The point, rather, is that the intuitionism of Ross is not a reason for which he should be kept out of the fold of the standard approach to business ethics, since the staples of the standard approach also cohere with, if not straightforwardly endorse, a similar epistemology of requirement. Recall that we were addressing the potential No-Objectivity criticism to a Rossian business ethic, according to which Ross's theory cannot provide any objective grounding for claims about right and wrong. I hope it is now clear that such a criticism would either itself be subject to criticism or, at best, would be disingenuous from those endorsing the standard approach.

\subsection{Rossian Rewards: Potential Benefits to Business Ethics}

If the foregoing is correct, then insights usually thought reserved for particularists are indeed available to generalists (and, therefore, to those of the standard approach to business ethics). Chief among these insights are the plausibility of holism and pluralism and the defeasibility of ethical principles. The possibility of a Rossian

\footnotetext{
${ }^{29}$ See Stratton-Lake (2016) for demonstration of similar thinking in the more sophisticated consequentialisms of Sidgwick and Moore.

${ }^{30}$ Even while resisting particularism and remaining sympathetic to Kantianism, Smith and Dubbink (2011, 212-13,225) seem to concede that there are no meta-rules in business ethics—as do Lurie and Albin (2007, 203-6) in their acceptance of what they call "casuistry."
} 
business ethic - which is holist, pluralist, and generalist-illustrates that standard approaches to business ethics need not be opposed to all aspects of particularist thinking. Suppose that business ethicists take my recommendation and devote more resources to developing Rossian business ethics. What might be their rewards for such devotion? While I do not here have the space to outline all such potential, I will briefly gesture toward five ways that Rossian thinking could push the field forward.

First and foremost, I want to suggest that reasoning like a Rossian is its own reward in that it will help ethicists and businesspersons to improve their sense of what features are deliberatively relevant in a given situation. I argued (in section 2.3) that holism and pluralism are plausible views of moral metaphysics and (in section 2.2) that a competent and mature moral thinker will apprehend the ethical landscape as it really is. If holism and pluralism are correct theories of moral metaphysics, then the one who pivots toward Rossian thought will be rewarded with more of the ethical truth than they were previously grasping.

Second, and relatedly, reasoning like a Rossian can encourage ethicists and businesspersons to develop their ability to empathize with those who think or act wrongly or differently. In some ways, this is an application of a point I made earlier (in section 2.3) — that holistic and pluralistic thinking encourages moral imagination and sensitivity, whereas atomism and monism encourage a kind of moral myopia. For example, a supervisor stuck in simple utilitarian thinking might wonder, "How on earth could he have thought that blowing the whistle was the right thing to do?! Look at all the jobs and revenue it cost us!" The Rossian, however, is able to genuinely countenance the idea that, in addition to the duty of producing happiness for others, there are duties, perhaps satisfied by an act of whistleblowing, to repair wrongs and rectify injustices. I would suggest that the simple thought that others might have been tending to duties or values - genuine duties and values - other than those we had in mind can help us to better and more charitably understand the choices that others make. ${ }^{31}$

Third, and now more theoretically, a Rossian theory can help us to do justice to the idea of a moral dilemma in business-but without dooming us to despair. ${ }^{32}$ As I illustrated in section 2.3, we often find natural (and reasonable!) the feeling that we have multiple, conflicting duties in a given situation. Monistic theories, in adhering to just one fundamental duty or value, must ultimately dismiss these feelings (reasonable as they might seem) as misleading. After all, on these views, there is just one fundamental principle; no (true) principle can conflict with itself. The Rossian, on the other hand, can paint an intuitive picture of these intuitive thoughts. Why might it seem, even to a sensible businessperson, both that the price of this drug should be raised and that the price of this drug should be lowered? If this were a mere

\footnotetext{
${ }^{31}$ It is ultimately inconsequential to the present point whether the hypothetical whistleblowing is right or wrong. Instead, the point is that acknowledging a plurality of duties and values could soften the supervisor to the thought that the whistleblower might have had good reasons for doing what he did.

${ }^{32}$ The term moral dilemma is sometimes used to refer merely to a difficult choice or a situation in which you have a duty to do something that you do not want to do (or that would not benefit you). Here I use the term as is standard in metaethics: a moral dilemma is a situation in which one is genuinely required to do, but cannot do, two different acts.
} 
consequentialist calculus (for example), one of these seemings should dissolve. But that is not how we often experience difficult choices in business. Instead, the Rossian hypothesizes, the felt tension here is due to the fact that one might have genuinely conflicting duties (a duty of fidelity to maximize gains for shareholders and a duty of beneficence to serve patients, for example). The fact that one of these things is ultimately the right thing to do does not completely eliminate the feeling of tension, because there really was some measure of (as Rossians say) genuine prima facie rightness lent even to the action that ought not have been done. Development of Rossian resources, I think, promises to help us better understand and analyze moral dilemmas in a way that more truly resonates with the experience of businesspersons. ${ }^{33}$

Fourth, and relatedly, a Rossian theory is uniquely situated to capture the diversity of and complexity among stakeholders and their normative interrelations. There has long been momentum pushing business ethicists toward the thought that business does not exist solely to serve shareholders; it must tend to the interests of various stakeholders. But the wisdom of this proposal is potentially mired by problems; difficult questions arise, for example, as to who counts as a stakeholder and how businesspeople ought to weigh competing concerns of various stakeholders. The Rossian framework has the potential to organize and clarify our thinking about these issues. While standard generalist theories "simplify unduly our relations to others," a Rossian framework might allow us to better account for the variation in ethically significant relationships among those in business. ${ }^{34}$ Perhaps part of the reason that we think shareholders are special, for example, is that employees (explicitly or implicitly) promise to serve their interests, perhaps in return for the benefits that they offer. In Rossian terms, businesspeople owe special duties of fidelity and gratitude to shareholders; this distinguishes obligations to shareholders from (for example) a general duty of beneficence impartially owed to all stakeholders. As such, although it would be incredibly shortsighted to attend only to the interests of shareholders, it would likewise be too simplistic to treat shareholders just like any other stakeholder. This is only one small sample as to how a Rossian framework could shed further light on our thinking about shareholders and stakeholders. ${ }^{35}$

Fifth, Rossian thinking can provide a uniquely constructive critical soundboard for each of the other major theories in business ethics. We have already seen how the Rossian might push utilitarians and Kantians to improve their thinking. Take for another example the (very promising) market failures approach (MFA), most

\footnotetext{
${ }^{33}$ I cannot fully pursue this idea here, and even what I have said, I have said quickly. For example, the utilitarian can say of a dilemma that even the wrong action had a certain measure of goodness to recommend to it (whatever pleasure it might have caused, for example). But it cannot say that there was any rightness in it, for on the utilitarian view, rightness is all-or-nothing.

${ }^{34}$ See Ross ([1930] 2009, 19), who says this of "ideal utilitarian" theories, which incorrectly imply that "the only morally significant relation in which my neighbours stand to me is that of being possible beneficiaries by my action." I leave it to the reader to see how one could make a similar critique of any standard theory which is both atomistic and monistic.

${ }^{35}$ In fact, my own view is that a Rossian framework can provide a solution to what Goodpaster (1991) called the stakeholder paradox. I cannot provide that solution fully here, but I believe that the key lies in Ross's ([1930] 2009, 24) denial of the claim that "every act that is our duty is so for one and the same reason."
} 
notably developed by Joseph Heath $(2006,2014)$. As I understand it, the dictum not to exploit market failures ultimately rests on an appeal to the value of efficiency. It is unlikely that this could be the whole story, though, since 1) it seems obvious that there are good-making features, relevant to business, other than efficiency, and 2) efficiency does not seem to be intrinsically valuable - it is not an end in itself. On the first front, the Rossian enumerates at least virtue, justice, knowledge, and happiness as fundamental good-making features (ultimate values) in business; on the second front, the Rossian observes that the value of efficiency seems to be parasitic on the value of the thing more efficiency produced. It would seem, then, that in orderto leverage lasting insight out of the MFA, it needs to be couched in a more complete theory of value. ${ }^{36}$ My own suspicion is that the MFA has identified a unique societal role that business plays in producing and distributing the basic good of happinessbut following through on that suspicion is a task for another time. The present point is only that theories of business ethics, both well established and newly developed, would benefit from interaction - even critical interaction—with Rossian thought.

\section{CONCLUDING REMARKS}

Allow me to take stock and more concisely state what I hope to have shown. The standard approach to business ethics is most essentially a generalist one: it assumes that facts about right and wrong in business, and our apprehension of those facts, depend on a suitable supply of moral principles. Particularism denies this. These are metaphysical claims, concerning the nature of ethical judgment and reality. As such, it would be infelicitous to resist the presence of particularism in business ethics for the reason that it does not give us concrete practical guidance in business situations: particularism is simply not in the business of trying to provide any such. It would also be self-defeating: no standard normative or meta-ethical theory by itself delivers concrete verdicts about what is to be done in specific cases, how to deliberate about that matter, or unobjectionable grounds for claims about what should be done such that the conclusion could not be resisted. Instead, every theory relies, at some point, on the use of what we might call intuition. So, although particularism does (by itself) not give us solutions to concrete ethical problems (or rigid procedures for discovering them), this is not a shortcoming of particularism, and particularism has just as much of a claim to providing objective grounds for claims about right and wrong as any theory accepted by the standard approach.

It remains the case, though, that if the standard approach to business ethics is a generalist approach, it can make no room for a wholly particularist approach: particularism and generalism are fundamentally at odds. However, in making the case for particularism, ethicists have unveiled persuasive arguments for holism and pluralism, which essentially tell us that the moral landscape in which we make

\footnotetext{
${ }^{36}$ Note that even Heath $(2006,549-52)$ seems to concede that it is only our duties in "extrafirm" contexts which are governed by the dictum not to exploit market failures (and therefore ultimately propped up by the value of efficiency). Our duties in "intrafirm" contexts are governed by principles similar to that of "the shareholder-focused view" (549). Thus, even by Heath's own lights, the MFA is in need of a unifying theory which accommodates both kinds of duties.
} 
important decisions in business might be much more complex than a flatfooted generalism might lead us to suppose. These theories, though metaphysical, provide practical wisdom for business ethics by encouraging us to 1) expand our moral imagination and sensitivity, paying attention to the whole character of acts, rather than to single, isolated features; 2) appreciate the moral risk we may incur by deliberating only in terms of one kind of morally relevant feature or value; and 3) subject to greater scrutiny the principles of business ethics we tend to take for granted. This practical wisdom is accessible to those favoring the standard approach to business ethics, their generalism notwithstanding, as evinced in the possibility of a Rossian business ethic (which is generalistic, pluralistic, and holistic). Appreciation and application of this practical wisdom, I have also suggested, promise to reward the field with new insights to and enlightening analyses of pressing problems - both theoretical and practical—in business.

I make no claim here as to whether the standard approach is best or whether a particularist approach would be better; neither do I make any bold claim that a Rossian business ethic is the true business ethic. Indeed, I have raised no real critique of the standard approach outside its arguments against particularism. These are subjects for further inquiry. I do hope to have illustrated how a Rossian business ethic could accommodate some of the practical wisdom of particularism which would not otherwise be adequately represented in the standard approach and also to have removed a barrier to countenancing this wisdom by showing that it is not at odds with generalism. ${ }^{37} \mathrm{I}$ hope, then, to have at least persuaded those partial to the standard approach of my modest proposal: bring the work of Ross further into the fold and engage more meaningfully with his work. One does not have to be unprincipled to find guidance for business ethics in his work; he is, for practical purposes, particularism for generalists.

\section{Acknowledgements}

I thank several audiences, most notably that at the Society of Business Ethics meeting in August 2019, for feedback on early versions of this article. I also thank several anonymous referees (both at that conference and for this journal) and several editors of this journal (especially Andrew Wicks and Norman Bowie) for feedback. I have been particularly aided by helpful conversations with and feedback from Robert Audi and Jeffery Smith. I am also grateful to Eric Peterson, who read and discussed several drafts and ideations of this article. A greater deal of credit belongs to Alexei Marcoux and Andy Gustafson for providing all of the above, but even more so for first encouraging me to embark on this project and for helping me understand how to engage the field of business ethics. I am above all indebted to Jonathan Dancy, who taught me more than anyone how to think about these things.

\footnotetext{
${ }^{37}$ Thanks to an anonymous referee, who worries that, in saying this, I contradict earlier claims that set up generalism as being at odds with particularism. Lest there be any confusion: I maintain throughout the taxonomy offered by Dancy (presented above in section 2.2), on which particularism and generalism are fundamentally at odds. I do not here argue that the disagreement between particularism and generalism is merely an apparent one. Instead, my argument, in a sense, has been that this disagreement does not entail that the generalist need reject all positions usually associated with particularism (most saliently: holism and pluralism).
} 


\section{REFERENCES}

Arnold, Denis G., Robert Audi, and Matt Zwolinski. 2010. "Recent Work in Ethical Theory and Its Implications for Business Ethics." Business Ethics Quarterly 20 (4): 559-81.

Audi, Robert. 2001. “A Kantian Intuitionism.” Mind 110 (439): 601-35.

Audi, Robert. 2004. The Good in the Right: A Theory of Intuition and Intrinsic Value. Oxford: Oxford University Press.

Audi, Robert. 2008. Business Ethics and Ethical Business. Oxford: Oxford University Press. Bonevac, Daniel. 2016. "Defaulting on Reasons." Nous 1 (1): 1-31.

Brink, David. 2018. "Mill's Moral and Political Philosophy." In Stanford Encyclopedia of Philosophy, Winter ed., edited by Edward N. Zalta. https://plato.stanford.edu/entries/ mill-moral-political/.

Carson, Thomas. 1993. "Second Thoughts about Bluffing.” Business Ethics Quarterly 3 (4): $317-41$.

Carson, Thomas. 2005. "The Morality of Bluffing: A Reply to Allhoff." Journal of Business Ethics 56 (4): 399-403.

Carson, Thomas. 2010. Lying and Deception: Theory and Practice. Oxford: Oxford University Press.

Dancy, Jonathan. 2004. Ethics without Principles. Oxford: Oxford University Press.

Dancy, Jonathan. 2009. "Moral Particularism." In Stanford Encyclopedia of Philosophy, Spring ed., edited by Edward N. Zalta. https://plato.stanford.edu/entries/moralparticularism/.

Goodpaster, Kenneth E. 1991. "Business Ethics and Stakeholder Analysis.” Business Ethics Quarterly 1 (1): 53-73.

Gustafson, Andrew. 2019. "Dancing with Dancy: Can Particularists Be Business Ethicists?" Unpublished manuscript.

Heath, Joseph. 2006. "Business Ethics without Stakeholders.” Business Ethics Quarterly 16 (4): 533-57.

Heath, Joseph. 2014. Morality, Competition, and the Firm: The Market Failures Approach to Business Ethics. Oxford: Oxford University Press.

Horty, John F. 2012. Reasons as Defaults. Oxford: Oxford University Press.

Kaebnick, E. G. 2000. "On the Intersection of Casuistry and Particularism." Kennedy Institute of Ethics Journal 10 (4): 307-32.

Kuczewski, M. G. 1997. Fragmentation and Consensus: Communitarian and Casuist Bioethics. Washington, DC: Georgetown University Press.

Little, Margaret Olivia. 2000. "Moral Generalities Revisited." In Moral Particularism, edited by Brad Hooker and Margaret Olivia Little, 276-304. Oxford: Oxford University Press.

Lurie, Yotam, and Robert Albin. 2007. "Moral Dilemmas in Business Ethics: From Decision Procedures to Edifying Perspectives.” Journal of Business Ethics 71 (2): 195-207.

Moriarty, Jeffrey. 2017. “Business Ethics.” In Stanford Encyclopedia of Philosophy, Fall ed., edited by Edward N. Zalta. https://plato.stanford.edu/entries/ethics-business/

Plato. 1997. Complete Works. Edited by John M. Cooper. Indianapolis, IN: Hackett.

Ridge, Michael, and Sean McKeever. 2005. "What Does Holism Have to Do with Particularism?" Ratio 18 (1): 93-103.

Ridge, Michael, and Sean McKeever. 2006. Principled Ethics: Generalism as a Regulative Ideal. Oxford: Oxford University Press. 
Ridge, Michael, and Sean McKeever. 2016. "Moral Particularism and Moral Generalism.” In Stanford Encyclopedia of Philosophy, Winter ed., edited by Edward N. Zalta. https:// plato.stanford.edu/entries/moral-particularism-generalism/.

Ross, William David. (1930) 2009. The Right and the Good. 2nd ed. Oxford: Oxford University Press.

Ross, William David. 1939. Foundations of Ethics. Oxford: Oxford University Press.

Ryle, Gilbert. 1949. The Concept of Mind. 60th anniversary ed. Chicago: University of Chicago Press.

Schneewind, J. B. 1970. "Moral Knowledge and Moral Principles." In Knowledge and Necessity, edited by G. N. A. Vesey, 249-62. New York: Macmillan.

Smith, Jeffery, and Wim Dubbink. 2011. "Understanding the Role of Moral Principles in Business Ethics: A Kantian Perspective.” Business Ethics Quarterly 21 (2): 205-31.

Stratton-Lake, Philip. (2002) 2007. Introduction to The Right and the Good, edited by Philip Stratton-Lake, ix-lviii. Oxford: Oxford University Press.

Stratton-Lake, Philip. 2016. "Intuitionism in Ethics." In Stanford Encyclopedia of Philosophy, Winter ed., edited by Edward N. Zalta. https://plato.stanford.edu/entries/ intuitionism-ethics/.

Werhane, Patricia H. 1999. Moral Imagination and Management Decision Making. Oxford: Oxford University Press.

Werhane, Patricia H. 2010. "Principles and Practices for Corporate Responsibility." Business Ethics Quarterly 20 (4): 695-701.

Williams, Bernard. 1985. Ethics and the Limits of Philosophy. Cambridge, MA: Harvard University Press.

J. Drake (jdrake@creighton.edu) is a teaching fellow in ethics and resident assistant professor at Creighton University. He earned his PhD from the Department of Philosophy at the University of Texas at Austin. His research focuses on the intersection of ethics and epistemology, especially as connected to action theory and practical reasoning. 